* Professora Celetista na Universidade Norte do Paraná (UNOPAR) e na Anhanguera Educacional (AEDU). Professora vistitante no Instituto Superior de Administração e Economia (ISAE - FGV). Mestre em História, Especialista em História e Humanidades e Graduada em História pela Universidade Estadual de Maringá (UEM). Graduada em Direito pela Universidade Estadual de Londrina (UEL). E-mail: patygrazy@hotmail.com

** Professor Associado da Universidade Estadual de Maringá (UEM), atuando no Programa de Pós-Graduação em História e no Departamento de História. Pós-Doutor em História pela Universidade Federal de Minas Gerais. Doutor e Mestre em História e Sociedade pela Universidade Estadual Paulista Júlio de Mesquita Filho. Graduado em História pela Universidade Estadual de Londrina

E-mail: angelopriori@uem. br

\section{Percepções Jurídicas Acerca Dos Movimentos Grevistas No Brasil Em Meados Do Século XX}

\author{
Legal Perceptions Of The Striker Movements In \\ Brazil In The Mid Twentieth Century
}

Como citar: GONÇALVES, Patrícia Graziela; PRIORI, Angelo Aparecido. Percepções jurídicas acerca dos movimentos grevistas no Brasil em meados do século XX. Revista do Direito Público, Londrina, v. 14, n. 1, p. 121-138, abr. 2019. DOI: 10.5433/1980-511X2019v14n1p121. ISSN: 1980-511X.

Resumo: O trabalho apresenta os resultados de uma pesquisa que objetivou analisar o pensamento jurídico acerca dos movimentos grevistas ocorridos no Brasil em meados do século XX, tendo como fonte artigos escritos por juristas e publicados na Revista Forense e na Revista dos Tribunais entre os anos de 1953 e 1955. Para o desenvolvimento de nossas reflexões, partimos do pressuposto de que os acontecimentos sociais possuem reflexos importantes no âmbito jurídico, propiciando a interiorização de esquemas de percepção, apreciação e ação por parte dos diversos agentes jurídicos. Como resultado, identificamos os diferentes modos de percepção dos referidos movimentos sociais: as associações entre greve e guerra; as críticas ao seu sentido político; as suas desqualificações em termos legais; e também algumas defesas.

Palavras-Chave: Direito de greve. Revistas jurídicas. Pensamento jurídico.

Abstract: This paper investigates the legal understanding of striker movements in Brazil during the mid-twentieth century. To this end, this paper analyzes research articles written by lawyers and legal scholars published in Revista Forense and Revista dos Tribunais between the years of 1953 and 1955. In order to develop our ideas, we assumed that social events have 
important consequences in the legal framework, leading to the internalization of perception, appreciation and action by various jurists. As a result, we identify different forms of perception of these historical and social movements: the associations between strike and war; criticism of the political sphere; the disqualifications of legal terms, and some legal defenses.

Keywords: Right do strike; legal periodicals; legal thinking. 


\section{INTRODUÇÃO}

As greves ocorridas no Brasil em meados do século XX já foram objeto de análise de diversos trabalhos no campo da história, bem como em áreas afins. Como exemplos, temos: a pesquisa de Hélio da Costa (1995), que analisou a organização dos trabalhadores brasileiros nas comissões de fábrica e sindicatos, os movimentos grevistas e o papel do Partido Comunista Brasileiro (PCB) nesse cenário; o estudo de Marcelo Badaró Mattos (2004), que analisou as greves e a repressão aos sindicatos no Rio de Janeiro entre 1954 e 1964; e a pesquisa de Antonio Luigi Negro e Fernando Teixeira da Silva (2008), enfocando a relação entre trabalhadores, sindicatos e política no chamado período democrático, ou seja, entre 1945 e 1964.

No entanto, uma análise aprofundada sobre o pensamento jurídico acerca desses movimentos sociais ainda está por ser feita e esse trabalho tem o intuito de levantar algumas reflexões iniciais. Isto porque, um enfoque nas percepções jurídicas nos permitirá compreender mais um aspecto desse tema multifacetado. Vale ressaltar que a escolha do pensamento jurídico como objeto de estudo se justifica justamente porque nele encontramos uma fonte importante para a compreensão do estabelecimento de "práticas sociais e ideológicas, a partir das quais se difunde uma forma particular de se pensar a organização social” (NEDER, 1995, p. 11).

Para o desenvolvimento de nossas reflexões, partimos do pressuposto de que os acontecimentos histórico-sociais possuem reflexos importantes no âmbito jurídico, propiciando a interiorização de esquemas de percepção, apreciação e ação por parte dos diversos agentes jurídicos. Sendo assim, nesta pesquisa, trabalhamos com as formulações do pensamento jurídico, contidas em seus discursos, sobre comportamento dos segmentos sociais participantes dos movimentos grevistas nos grandes centros urbanos na década de 1950, levando em conta suas articulações com as condições históricas que as produziram.

As fontes documentais selecionadas constituem-se de artigos escritos por juristas e publicados na Revista Forense e na Revista dos Tribunais ${ }^{l}$ entre os anos de 1953 e 1955. Cabe ressaltar que os periódicos constituem um rico material de análise histórica, uma vez que os mesmos permitem que os debates acerca dos padrões socioculturais circulem mais rapidamente em função de sua periodicidade. O uso dessa fonte permite acompanhar as mais variadas discussões jurídicas, já que abre espaço para os temas que estão em evidência no país. Com isso, é possível verificar como o pensamento jurídico reage às transformações sociais, políticas, econômicas e culturais ocorridas na sociedade.

Sobre a Revista Forense, esta foi criada em 1904 pelo advogado e jornalista Francisco Mendes Pimentel e pelo advogado Estevão Magalhães Pinto. A partir de 1935, a Revista passou a ser dirigida por Pedro Aleixo e pelo professor de Direito da então Universidade de Minas Gerais, hoje UFMG, Bilac Pinto. Era publicada em Belo Horizonte, pela Imprensa Oficial do Estado de Minas Gerais, até 1936, quando foi transferida para o Rio de Janeiro e passou a ser publicada pela

1 As coleções de ambas as revistas foram encontram-se disponíveis no setor de periódicos da Universidade Estadual de Maringá (UEM). 
Oficina Gráfica Mandarino e Molinari.

Já a Revista dos Tribunais foi lançada em 1912 pelo advogado e jornalista Plínio Barreto, como uma extensão do antigo informe jurídico Crônicas Forenses, do jornal O Estado de São Paulo. Desde o início, a publicação ocupou uma posição de destaque na imprensa especializada do setor. A iniciativa alcançou êxito imediato porque, na época, as obras científicas eram uma novidade: o país era uma vastidão de terras inexploradas e as poucas bibliotecas se restringiam às capitais.

$\mathrm{Na}$ análise das fontes documentais, seguindo as orientações de Georges Duby (1979), procuramos descobrir os termos reveladores e, mais que as palavras, as apresentações, as metáforas e a maneira pela qual os vocabulários se acham associados, que refletem inconscientemente a imagem que um grupo ou segmento social, num dado momento, possuí de si próprio e dos outros, no nosso caso, os agentes jurídicos. Nesse sentido, trabalhamos com vestígios e indícios, tal como indicou Carlo Ginzburg (2003), o que nos permite extrair das fontes a riqueza simbólica do pensamento jurídico sobre os movimentos grevistas na sociedade do período. Atentando para esses sinais e indícios, ao analisarmos o discurso produzido pelos agentes jurídicos, observamos com mais atenção as condições sociais em que foi produzido.

Por fim, não pudemos negligenciar o fato de que o discurso jurídico é produzido a partir de um habitus linguístico, para usarmos um conceito de Pierre Bourdieu (1998), o que implica certa propensão a falar e a dizer coisas determinadas, com um discurso estilisticamente caracterizado que lhe confere, ao mesmo tempo, uma competência técnica e uma capacidade social para usá-lo em situações determinadas.

\section{OS MOVIMENTOS GREVISTAS}

O Brasil de meados do século XX vivenciou um período de excepcional crescimento e desenvolvimento econômico, devido à intensificação do processo de industrialização e urbanização ocorrido nas grandes cidades. Estava presente na sociedade brasileira um forte ideário de modernização e um clima de euforia decorrente do processo de democratização política e do fim da Segunda Guerra Mundial. Aliado a isso, a nova Constituição Brasileira, promulgada em 1946, possuía uma roupagem mais liberal e democrática, trazendo algumas garantias sociais, tais como a organização da ordem econômica baseada nos princípios de justiça social, devendo conciliar a liberdade da iniciativa privada com a valorização do trabalho humano, garantindo, inclusive, o direito de greve.

Mas a sociedade brasileira desse período foi paradoxalmente marcada pelo desenvolvimento econômico e pela acentuação dos desequilíbrios e as desigualdades já existentes, persistindo acentuados níveis de pobreza no país. O quadro de carência generalizada, concomitantemente ao desenvolvimento econômico e ao influxo populacional provocado por grandes correntes migratórias internas, gerou uma significativa conflitividade social em vários âmbitos. Dentre os que mais se destacam, os protestos populares e as greves, nas quais se reivindicava a redução dos 
custos de vida e a melhora dos salários.

Em trabalho sobre as greves e a repressão aos sindicatos no Rio de Janeiro de meados do século XX, Marcelo Badaró Mattos (2004) rediscutiu a relação entre Estado, empresários e trabalhadores organizados a partir da dimensão de conflito explicitada nos momentos de greve. $\mathrm{O}$ autor afirmou existir certa dificuldade em precisar o número de greves ocorridas nas décadas de 1950 e 1960, pois não havia estatísticas oficiais de greves até pelo menos a década de 1980. De acordo com os dados apurados por Mattos, foram realizadas 480 greves entre os anos de 1945 e 1954 somente naquele Estado. Apenas no período de 1958-1963 o autor localizou 307 greves.

Marcelo Badaró Mattos (2004) assinalou que o primeiro momento das paralisações no período foi em 1946, seguido de dois anos de quase completa inexistência de movimentos grevistas. E "nos anos seguintes, até meados da década de 1950, mantém-se, com oscilações, um patamar semelhante e uma continuidade de atividades grevistas, com cinco greves no ano de mais baixa atividade (1951) e 23 paredes no ano de maior agitação (1956)" (MATTOS, 2004, p. 243). Mas é na segunda metade da década de 1950 e início da década de 1960 que "a curva de movimentos grevistas toma um rumo ascendente significativo, com saltos sucessivos no número de paralisações, que configuraram uma das fases mais dinâmicas do movimento operário brasileiro" (MATTOS, 2004, p. 243).

Analisando as estatísticas das greves entre as décadas de 1950 e 1960, Marcelo Badaró Mattos (2004) afirmou que os números questionavam tanto a ideia de que havia um predomínio de greves por categoria quanto a de que elas se organizavam "de fora pra dentro da empresa", com a realização de piquetes a partir da decisão de direções sindicais distantes da sua base. Isso porque, para se fazer a greve era necessário um nível de organização no local de trabalho (OLT), sendo este elemento identificado em diversos estudos sobre essa conjuntura. Sendo assim, "a presença das OLTs atravessa todo o período, em categorias industriais, como os metalúrgicos e os têxteis, em categorias manufatureiras, como os marceneiros, e em categorias do setor de serviços, como os bancários" (MATTOS, 2004, p. 246).

Sobre as reivindicações das greves, Marcelo Badaró Mattos (2004) analisou as estatísticas para o período e concluiu que havia "um predomínio de demandas econômicas, de uma forma ampla, ou mais especificamente de propostas de reajustes salariais, nas pautas de reivindicações dos movimentos grevistas” (MATTOS, 2004, p. 248). As pautas econômicas em predomínio não eram, segundo o autor, incompatíveis com as demandas políticas ou busca por garantia de direitos contra as decisões da própria Justiça do Trabalho.

Na verdade, em muitas greves suscitadas por motivos econômicos era colocada a dimensão do enfrentamento político. E em todas as greves buscava-se "garantir direitos conquistados, enfrentar a insistência dos patrões em descumprir acordos, ou denunciar a iniquidade de decisões judiciais" (MATTOS, 2004, p. 249). Assim, de acordo com Mattos, havia certo grau de politização em determinadas greves por demandas econômicas no setor de serviços como, por exemplo, nas greves do porto, nas quais o governo "acoplava o atendimento do pleito de reajuste a uma subsequente compensação da empresa através de um aumento proporcionalmente maior das 
tarifas" (MATTOS, 2004, p. 250).

A melhoria das condições de trabalho também motivou muitas greves, demonstrando que o movimento organizado não desconhecia o dia-a-dia de exploração das empresas sobre os trabalhadores. E mais, "atentar para as condições de trabalho poderia ser até mesmo uma chave para mobilizar os trabalhadores para demandas mais gerais" (MATTOS, 2004, p. 250). Já as greves de solidariedade demonstravam por sua vez que nem sempre as motivações eram de natureza material, e que eram bastante expressivos nesse período os sentimentos de pertencimento a uma classe e de representatividade das organizações sindicais. Além disso, a defesa da representação sindical nas empresas, tanto como reivindicação principal quanto associada a outras, moveu várias greves no período.

Além disso, as greves por solidariedade demonstram que a estrutura sindical não conseguiu compartimentar completamente as lutas da classe trabalhadora nas gavetas estanques das categorias. Muitas foram movidas, mostrando que, para além dos organismos intersindicais, criados muitas vezes em meio às greves, $\mathrm{o}$ impulso das demonstrações concretas de unidade na luta atravessava os mais diversos momentos (MATTOS, 2004, p. 252).

Dessa forma, fica evidente que as motivações para as greves nem sempre eram apenas de cunho econômico, como a reivindicação de aumento salarial e redução dos custos de vida, mas também por melhorias das condições de trabalho e influenciadas por fatores de cunho político. Conforme os anos passavam, os trabalhadores procuraram com mais força interferir no processo político, almejando não apenas materializar seus direitos políticos, "mas também a expectativa de ampliação das dimensões políticas e sociais de um regime que se pretendia democrático" (MATTOS, 2004, p. 255).

Em se tratando do período delimitado por nossas fontes (1953-1955) para a análise das percepções jurídicas sobre os movimentos grevistas, temos que no início da década de 1950 havia um grande descontentamento entre os trabalhadores urbanos e organizados em sindicatos. Isto porque desde a eleição de Getúlio Vargas (1951-1954) as expectativas de melhorias aumentaram entre os trabalhadores, bem como as suas mobilizações, uma vez que Vargas se elegeu justamente com promessas dessas melhorias.

O fato é que houve uma expansão do movimento sindical, reprimido durante o governo anterior de Gaspar Dutra (1945-1950) e, somado a essas questões, a inflação e o custo de vida subiram bem mais que o salário mínimo durante os anos de 1951 e 1952. Desse modo, o resultado das difíceis condições salariais e maior liberdade para a mobilização sindical foi um grande número de greves, sendo o ano de 1953 é histórico pela ocorrência de experiências grevistas importantes.

De acordo com Antonio Luigi Negro e Fernando Teixeira da Silva (2008), em 1953 ocorreu a Greve dos 300 Mil em São Paulo. Tendo sido iniciada na fábrica de tecidos Matarazzo, logo se alastrou para outras categorias, tais como metalúrgicos, vidreiros, marceneiros e gráficos. Suas reivindicações iniciais "limitavam-se ao aumento salarial de $60 \%$, estabilidade no emprego e 
exigência de medidas governamentais contra a carestia" (NEGRO; SILVA, 2008, p. 63). Esta greve foi liderada pelo comunista Antonio Chamorro e foi bem recebida pela população em geral, preocupada com a carestia. As manifestações de rua foram ampliadas e lideranças oriundas do "chão das fábricas" tornaram-se protagonistas do movimento.

Em importante estudo sobre a Greve dos 300 Mil, José Álvaro Moisés (1978) descreveu e analisou alguns aspectos relevantes da participação política dos trabalhadores no Brasil, notadamente no referido movimento grevista. Salienta o autor que tal greve se inseriu num contexto político peculiar, marcado pela eleição de Jânio Quadros para a prefeitura de São Paulo e um pouco antes da escolha de João Goulart para o Ministério do Trabalho², durante a segunda administração de Vargas. A análise desse movimento grevista possibilitaria entender a capacidade de organização dos trabalhadores, partindo de suas circunstâncias próprias e particulares.

Entendendo a greve como uma situação de conflito entre classes, numa perspectiva claramente marxista, José Álvaro Moisés (1978) ressaltou que não era possível ignorar os fatores (com ênfase no populismo de Vargas) que influenciaram a emergência e o desenvolvimento da greve. Do mesmo modo, não poderia ignorar a existência da arbitragem por parte do Estado no episódio da greve, a qual beneficiou um dos lados envolvidos no conflito. E mais, as intervenções em greves, como o uso da força policial e outros mecanismos de repressão da greve, possuíam o claro objetivo de reprimir a ação coletiva, com um caráter abertamente favorável a um dos lados da disputa.

A Greve dos 300 Mil em São Paulo durou 29 dias e deu origem a violentos choques entre os trabalhadores e a polícia, "resultando, entretanto, numa importante vitória para o movimento operário.” (MOISÉS, 1978, p. 70). O fim da greve só se deu quando os operários presos durante a manifestação foram libertados. As ofertas dos patrões, consideradas inaceitáveis, foram rechaçadas pelos grevistas, que se negaram a discutir propostas conciliatórias feitas pelo Tribunal Regional do Trabalho, forçando "o governador do Estado a intervir como mediador, quando, na realidade, sua função era a de reprimir o movimento" (MOISÉS, 1978, p. 70).

\section{AS PERCEPÇÕES JURIDÍCAS}

Todo o cenário dos movimentos grevistas se refletiu no pensamento jurídico do período. Nos artigos publicados na década de 1950 na Revista Forense e na Revista dos Tribunais, vários juristas escreveram sobre os aspectos constitucionais das greves, sobre o seu sentido político e sobre o seu suposto caráter violento, associando-as às guerras, nas quais se tentaria conseguir pela força o que não havia sido conseguido pelo diálogo. Além disso, alguns consideravam que as "multidões reunidas" nos grandes centros urbanos representavam um possível perigo à ordem estabelecida.

Numa brevíssima análise histórica sobre o direito de greve, é possível observar que em fins

2 Tal escolha foi acompanhada de uma das mais sérias crises políticas vividas pelo país, a qual culminou na morte de Getúlio Vargas. 
do século XIX, o Código Penal de 1880 criminalizou a prática de greve violenta. A greve pacífica não era crime e o direito de greve passou a ser entendido como um direito pelos trabalhadores, juristas e pelo Poder Judiciário. Nesse sentido, não existia regulação nenhuma sobre o direito de greve e a única positivação era aquela que criminalizava a greve violenta. (SIQUEIRA, 2014)

No entanto, devido a efervescência do movimento operário brasileiro na Primeira República (1889-1930), a violência policial foi utilizada no combate do direito de greve, até mesmo da greve pacífica, que já havia sido reconhecida como direito pelo Poder Judiciário (inclusive pelo Supremo Tribunal Federal, em 1922). Dessa forma, os movimentos operários foram vítimas da violência policial que, em diversos momentos, parece ser o braço armado e criminoso das grandes empresas e das grandes fábricas. (SIQUEIRA, 2014)

Na Constituição de 1934, a positivação do direito de greve não aconteceu, mas o direito continuou sendo exercido e combatido na prática: "fazer greve não era crime, mas a greve era combatida como crime”. (SIQUEIRA, 2014, p. 124). Já na Constituição de 1937, que marca o início do Estado Novo (face mais violenta do Governo Vargas), o direito de greve é inserido como algo prejudicial: “Art. 139 [...] A greve e o lock-out são declarados recursos anti-sociais nocivos ao trabalho e ao capital e incompatíveis com os superiores interesses da produção nacional”.

O movimento operário viveu um momento de grande repressão. Ao menor sinal de greve, a polícia era enviada. Jornais do movimento operário, escritores importantes, como Jorge Amado (2011) e a historiografia relatam a violência que os trabalhadores sofriam. O movimento operário sofre com perseguições, prisões e violências, mas resiste e tenta ocupar lugares nos espaços deixados pela ditadura. O Decreto n. 1.237, de 2 de maio de 1939, que regulamenta a Justiça do Trabalho também positiva os crimes relacionados à greve. A repressão ocorria nas ruas e no Legislativo. Já o Código de Penal de 1940 criminaliza apenas a greve violenta. Elaborado com a presença de juristas de importância na época, e publicado via decreto presidencial, também segue a tradição de seu antecessor de 1890. (SIQUEIRA, 2014, p. 125).

Finalmente, o direito de greve foi reconhecido como um direito dos trabalhadores pela Constituição de 1946, mas com amplas restrições aos chamados serviços essenciais e industriais básicos. O texto constitucional manteve dois fundamentos da estrutura corporativista advinda do regime anterior: o imposto sindical e a possibilidade de o Estado intervir na vida sindical. De qualquer modo, ainda que de forma genérica, aquele texto constitucional colocou um fim nas proibições e sanções impostas pela Constituição de 1937, na qual a greve era encarada como um delito e considerada como um recurso antissocial e prejudicial à economia.

Os debates em torno do direito de greve na Constituição de 1946 também se direcionaram no sentido de incorporar a Justiça do Trabalho, instituída em 1941, ao Poder Judiciário, suplantando sua origem administrativa. De acordo com Mauricio Godinho Delgado e Gabriela Neves Delgado (2011), o Decreto-Lei n ${ }^{\circ} 9.777$ de 09.09.1946 estruturou o processo de incorporação da Justiça do Trabalho ao sistema judicial. A nova Constituição constitucionalizou a sua existência. Nos anos 
posteriores, a Justiça do Trabalho se solidificou "como instituição imprescindível à inclusão social, econômica e institucional de milhões de brasileiros emergentes à nova sociedade e economia recém-urbanizadas e industrializadas".

Mas, na verdade, de acordo com Larissa Rosa Corrêa (2011), mesmo com a instalação da Justiça do Trabalho (1941) e com a consolidação das Leis de Trabalho (CLT), direitos trabalhistas tiveram de ser "tecidos" no plano da realidade pelos próprios trabalhadores.

A Justiça do Trabalho se transformou em um terreno fértil para a construção de uma identidade da classe trabalhadora fomentada pela luta por direitos. A experiência no campo da lei possibilitava aos trabalhadores elaborar estratégias que lhes permitiam negociar com os patrões dentro dos limites do mundo legal. Enquanto os primeiros procuravam encontrar na legislação um espaço para garantir e reivindicar direitos, os empregadores tentavam encontrar qualquer brecha, ambiguidade ou contradição legal para impedir e, até mesmo, se esquivar dos deveres trabalhistas (CORRÊA, 2011, p. 216).

Dessa forma, sendo gratuita e caracterizada pela possibilidade de instauração oral de processos (dispensando, portanto, a presença de um advogado), a Justiça do Trabalho se tornou um importante mecanismo não apenas para que trabalhadores "tecessem" a lei, mas para a formação de uma consciência jurídica dos direitos trabalhistas por parte dos próprios trabalhadores que participavam do rito processual.

\subsection{Constituição de 1946 e direito de greve: entre críticas negativas e positivas}

Sobre os aspectos constitucionais da greve, o jurista Paulo Carneiro Maia escreveu um artigo em 1953 no qual considerou que o direito de greve estabelecido pela Constituição de 1946 era conflitante com o "mandamento" penal que vedava o ato de fazer justiça com as próprias mãos. Além disso, entendia que este era desnecessário na sociedade brasileira, que já possuía a Justiça do Trabalho, encarregada de resolver os problemas entre patrões e empregados. Nesse sentido, a greve seria "o império do arbítrio em substituição ao poder instituído para deslindar o conflito" (MAIA, 1953, p. 5). Maia recuperou os comentários do constitucionalista Carlos Maximiliano em seu "Curso de Direito Constitucional Brasileiro", de 1951, sobre o dispositivo constitucional que regulamentava o direito à greve:

A greve assemelha-se ao denominado direito de revolução: constituía uma revolta contra a onipotência do capital, um meio violento para forçar os patrões a melhorarem as condições do trabalho. Carece, quase totalmente, de fundamento nos países em que se instituíram processos regulares e suaves para dirimir os dissídios entre empregados e empregadores. Não se deve recorrer à força quando se tem à mão a justiça; desaconselha-se o remédio violento desde que existe o mais brando, o jurídico (MAXIMILIANO apud MAIA, 1953, p. 5-6). 
O mesmo posicionamento contrário ao direito de greve também pode ser verificado em um artigo escrito por Carlos Medeiros Silva, consultor da República, e publicado na Revista Forense em 1954. Sobre a regulamentação do direito de greve na Constituição de 1946, ressaltou que no artigo 158 estava expresso: "É reconhecido o direito de greve, cujo exercício a lei regulará" (SILVA, 1954, p. 7). No entanto, deixou clara sua posição contrária às greves ao afirmar que esta era uma "forma violenta de reivindicação" (SILVA, 1954, p. 7).

Da mesma forma, o jurista Davi Campista Filho, em artigo escrito no ano de 1955, se posicionou contrariamente ao direito de greve expresso na Constituição de 1946, considerando "perigoso o influxo da declaração constitucional" (CAMPISTA FILHO, 1955, p. 441). Para esse jurista, após o reconhecimento do direito de greve pelo artigo 158 da Constituição então vigente, aconteceram inúmeros fatos que deveriam servir de advertência ao legislador "valendo em premunição a investidas do trabalhismo que, certamente, fará do problema o ponto central de suas expansões demagógicas" (CAMPISTA FILHO, 1955, p. 441). E mais,

Os acontecimentos que nestes últimos anos desenrolaram-se no Brasil imprimem significação impressionante à importância dos fatos, perante os quais a atitude do legislador há de ser de extrema prudência e imparcialidade. Esses fatos, sob a luz do raciocínio que os explica projetam-se pela conjectura na lei a estatuir-se, revelando a gravidade das conseqüências cujo alcance na vida econômica do país seria dos mais funestos (CAMPISTA FILHO, 1955, p. 441).

Campista Filho escreveu que, em meio à aceleração histórica do período, era necessário rejeitar as improvisações e afastar o arbítrio, pois seria na fase de aceleração histórica que o direito postulava leis de interesse particular. Foi o que teria acontecido com a Constituição de 1946, que no clima inquietante de psicologia política e social, decorrente do retorno da democracia após longo período de letargia, num "regime popular, imbuído de ilusões socialistas e ávido de conquista, por extrema tolerância e temerosa complacência” (CAMPISTA FILHO, 1955, p. 442), expressou em seu texto o reconhecimento do direito de greve. E mais, "semelhante atitude roçava pela anarquia, de tantas que as produzem os governos populares" (CAMPISTA FILHO, 1955, p. 442).

Nas palavras desse jurista, "greve consiste na suspensão deliberada do trabalho por parte de operários no sentido de obter melhores salários ou de testemunhar solidariedade aos companheiros" (CAMPISTA FILHO, 1955, p. 442). Suas origens remontariam à Revolução Francesa, quando se declarou o direito ao trabalho e à livre profissão. Assim, tendo surgido do direito ao trabalho, teria evoluído como conquista para direito de cessão ou interrupção do trabalho.

Entendia Campista Filho que "a greve, virtude da súbita paralisação de uma indústria, inevitavelmente lhe produz gravíssimo prejuízo agravado por sua duração. Assim se revela seu caráter anti-social e antieconômico" (CAMPISTA FILHO, 1955, p. 443). O caráter antissocial decorreria quando o direito de interromper o trabalho transpassava a esfera individual para a coletiva, o que constituía um abuso desse direito. Já o caráter antieconômico se revelava quando, para alcançar seus fins, o grevista atacava a economia da indústria, ferindo os interesses da 
coletividade.

Dessa forma, para Campista Filho, "nada mais certo do que se aplicar o preceito do abuso do direito ao exercício do direito de greve, cuja intenção dolosa manifestava-se através dos meios empregados à sua efetivação" (CAMPISTA FILHO, 1955, p. 443). E mais, esses meios ilegítimos, para se conseguir algo por vezes legítimo, se constituiriam principalmente no desrespeito a liberdade de trabalho quando ocorriam atos de violência para forçar a adesão da coletividade.

Mas, em meio às críticas ao direito de greve expresso na Constituição de 1946, encontramos algumas defesas. Idélio Martins escreveu um artigo em 1954 ressaltando que o Brasil de meados do século XX adentrara em um período de rompimento com as amarras do passado e de afirmação dos princípios democráticos, devido, sobretudo, ao fim da Segunda Guerra Mundial e do Estado Novo (1937-1945) de Getúlio Vargas, considerado por muitos como um regime autoritário e de tendências fascistas.

Como argumento principal de sua defesa, Idélio Martins escreveu que "a elevação da greve a direito de natureza constitucional foi fenômeno que se observou em quase tôdas as constituições que se foram promulgando no Velho Continente" (MARTINS, 1954, p. 10) no período posterior a Segunda Guerra Mundial, cujo pioneirismo pertenceu à França ${ }^{3}$. Do mesmo modo, a Constituição do Brasil de 1946 assegurou o direito de greve em seu texto:

Os nossos Constituintes de 46, embalados em exacerbados ideais de libertação democrática, preocupados dramaticamente com a redemocratização do País, não hesitaram em 'reconhecer' a greve como direito, e um direito garantido por sólido arcabouço constitucional (MARTINS, 1954, p. 10).

Entendia Idélio Martins que, mesmo com as limitações impostas pelos constituintes ao direito de greve, devendo esta ser regulada pela lei, a sua proclamação representou no Brasil um rompimento definitivo com o passado, "com o regime em que se pesquisaram e se proclamaram diretrizes totalitárias" (MARTINS, 1954, p. 12), referindo-se ao governo de Vargas. Enfatizou que a nova Constituição rompera com o sistema previsto pela anterior (1937), na qual a greve havia sido considerada um recurso antissocial ${ }^{4}$.

Nessa mesma direção, Seabra Fagundes, advogado do Rio de Janeiro, em artigo publicado na Revista Forense em agosto de 1954, defendeu o direito de greve no Brasil, desde que esta mesma não acontecesse nos serviços públicos e nem tão pouco tivesse cunho político. Afirmou que a greve era um fenômeno próprio de sociedades capitalistas. Suas motivações advinham geralmente de reivindicações econômicas, mas poderia nascer de outras considerações: políticas,

3 Idélio Martins ressaltou a importância decisiva da Constituição francesa de 19 de abril de 1946 nos debates travados na Constituinte brasileira do mesmo ano, os quais culminaram na afirmação constitucional do direito de greve. Tal Constituição francesa afirmava que: "É reconhecido o direito de greve, cujo exercício a lei regulará". No entanto, afirmou que o projeto francês de abril de 1946 foi submetido a plebiscito e rejeitado. Nova Constituição francesa foi promulgada em 27 de outubro do mesmo ano, trazendo em seu preâmbulo a declaração de direitos, entre os quais o direito de greve. Mas o Brasil não teve tempo de ser influenciado pela nova Constituição francesa, e manteve em seu texto as limitações impostas pelo bem público às greves, as quais seriam reguladas pela lei.

4 A greve foi apresentada na Constituição de 1937 como um recurso "nocivo ao trabalho e ao capital e incompatível com os superiores interesses da produção nacional” (MARTINS, 1954, p. 12). 
de solidariedade, de ordem moral, dentre outras.

Defendeu Seabra Fagundes que na Constituição de 1937 o Brasil havia declarado a greve como um recurso antissocial e nocivo ao trabalho e ao Capital, sendo que a legislação ordinária impunha sanções aos empregados, associações profissionais e administradores envolvidos em tais movimentos. Mas que a partir da Ata de Chapultepec ${ }^{5}$, o presidente da República, Gaspar Dutra, no decreto $n^{\circ}$ 9.070, de 15 de março de 1946, "regulou a suspensão e o abandono coletivo do trabalho, vedando-os nas atividades fundamentais, mas deixando-os livres para o que classificou de acessórias" (FAGUNDES, 1954, p. 12).

Seabra Fagundes afirmou que tal decreto traduzia a "força inelutável do direito de greve como reivindicação do trabalhador" (FAGUNDES, 1954, p. 13). Na opinião desse advogado, entendeuse naquela ocasião a importância de consagrar o direito de greve e que havia, possivelmente, um sentimento constrangedor em torno de sua proibição na Constituição de 1937. Além disso, esse jurista considerou as greves um fenômeno social de forças inelutáveis, contra as quais as leis não podiam resistir.

No entanto, citando o artigo $158^{6}$ da Constituição de 1946, Seabra Fagundes enfatizou que era necessário "aceitar possíveis restrições ao exercício do direito de greve, não somente por se lhe impor forma conveniente, como também por se declararem as atividades que o comportam e o repelem" (apud FAGUNDES, 1954, p. 14).

$\mathrm{Na}$ opinião do jurista, se existiam direitos também deveria haver submissão às regras ou à ordem jurídica. E tal princípio abria caminho para limitações ao direito de greve, tal como a exclusão desse direito aos funcionários públicos, já que em sua percepção o Estado não visaria o lucro de um empregador privado, além de ser ele o detentor do poder.

\subsection{Preocupações com o possível sentido político das greves}

No entendimento do jurista Seabra Fagundes, as greves políticas não seriam contempladas pelo direito aludido no art. 158 da Constituição de 1946. Para esse advogado, a greve que a Constituição tinha em vista era a de fundo econômico, ou seja, aquele referente ao fenômeno da desigualdade. Ao invés disso, "a greve política é a subversão, é o direito de subversão, outorgado a quem quer que seja, agrupando-se a outras pessoas" (FAGUNDES, 1954, p. 15). Portanto, não admitiu a greve política porque a considerava como a vontade da minoria tentando intervir na máquina do Estado.

As críticas ao sentido político das greves também puderam ser percebidas nos escritos de outros juristas. Vale ressaltar que muitos movimentos grevistas da década de 1950 recebiam o apoio de líderes do Partido Comunista Brasileiro (PCB), que estava na ilegalidade desde 1947. De acordo com Hélio da Costa (1995), ao ser proibido, o PCB passou a apelar às massas contra a onda

5 Conferência Interamericana de Problemas da Guerra e da Paz, realizada em Chapultepec, México, em fevereiro de 1945, na qual o direito de greve foi declarado um direito social do operário, um dos direitos fundamentais do homem.

6 "É reconhecido o direito de greve, cujo exercício a lei regulará". 
repressiva que se abatia sobre o movimento sindical e seus membros também a assumiram a defesa da liberdade e autonomia sindical, criticando veementemente a estrutura sindical imposta pelo Estado. Ganharam força as organizações nos locais de trabalho, de onde surgiriam as estruturas alternativas e autônomas em relação ao Estado. O partido voltou-se para a formação de associações profissionais ou centros operários paralelos ao sindicalismo oficial.

O jurista Carlos Medeiros Silva, em artigo escrito em 1954, deixou clara sua preocupação com o sentido político da greve, empreendendo um discurso desqualificador de sua real função. Para esse jurista, a greve seria uma manifestação contestadora da ordem política vigente, tendo um caráter revolucionário e sendo liderado por "profissionais". Silva considerou oportunas suas observações em matéria de regulamentação do direito de greve. E ressaltou: "é preciso que o legislador ordinário não se deixe influir pelas opiniões extremadas e pelos espíritos teóricos e desassustados da realidade social" (SILVA, 1954, p. 11). E ainda frisou que não se poderia ter "ordem e progresso" em uma sociedade que admitisse a desordem como meio de capaz de resolver as reivindicações dos trabalhadores.

\subsection{Comparações entre greves e guerras}

Em se tratando de violência, alguns juristas associavam as greves com as guerras. Um deles foi Paulo Carneiro Maia, em seu artigo de 1953, no qual recuperou os escritos de Charles Gide ${ }^{7}$ sobre o caráter violento da greve e sua técnica que se assemelhava à guerra, da obra "Compêndio d'Economia política", de 1935. Concordando com as posições de Gide de que a greve era como que a guerra dos empregados, ressaltou que ela seria um "ato tipicamente de violência para uma reivindicação que não se compreende seja feita "quando se tem à mão a justiça"” (MAIA, 1953, p. 6). Mas reconheceu que a situação de desigualdade entre empregado e empregador reclamava uma solução mais rápida. No entanto, "não nos parece que uma solução coercitiva e violenta deva se sobrepor ao órgão especial de justiça instituído pela Lei das Leis" (MAIA, 1953, p. 6).

Essa percepção da greve associada à guerra também pode ser verificada em um artigo escrito por República Carlos Medeiros Silva, consultor da República, publicado na Revista Forense em 1954. Em seu entendimento, o recurso à greve teria tido causas diversas no decorrer do tempo, e "a luta dos trabalhadores, para melhoria de suas condições de vida, criaram uma mística da greve com instrumento de reivindicação que é preciso preservar em homenagem aos antigos combatentes, dizem os seus apologistas" (SILVA, 1954, p. 7-8). Na concepção desse jurista, a greve era o caminho encontrado por "revolucionários profissionais e agitadores políticos" (SILVA, 1954, p. 8) para a subversão social.

Para Carlos Medeiros Silva, além desses motivos haveria outro responsável pelas greves, qual seja "a ausência de órgãos idôneos e capazes de tomar conhecimento e de atender, na justa medida, as reivindicações dos trabalhadores" (SILVA, 1954, p. 8). Esses órgãos poderiam evitar

7 Charles Gide (1847-1932), professor do Collège de France, foi economista e historiador do pensamento econômico francês. 
a greve no plano nacional, tal como acontece com a guerra no plano internacional. Referia-se aos tribunais especializados, que seriam o caminho para a solução justa e oportuna das "reivindicações proletárias". Desse modo, lançou críticas a Constituição vigente, na medida em que:

Por forma incoerente, institui a Justiça trabalhista e assegura o direito de greve, como se a existência da primeira não fosse o veículo adequado à solução dos conflitos. A par da via judiciária, imparcial e fiel aos interesses permanentes da coletividade, abriu-se brecha para as reivindicações violentas (SILVA, 1954, p. 8).

Essa associação da greve com a guerra demonstra grande receio dos juristas em relação às massas, às multidões ${ }^{8}$ reunidas nas grandes cidades, as quais representavam um eminente perigo à ordem social. É interessante frisar que essa preocupação com as multidões no Brasil em meados do século XX se assemelhou com algo ocorrido em países como França e Inglaterra durante os seus respectivos processos de industrialização e urbanização, ocorridos entre os séculos XVIII e XIX ${ }^{9}$. Naqueles contextos, as multidões compostas pelos trabalhadores - que viviam em péssimas condições, em bairros operários superpopulosos e sem nenhuma infraestrutura - e as quais expressavam suas insatisfações em manifestações de rua, eram consideradas perigosas por sua suposta condição de vida deteriorada, se constituindo em grave ameaça social.

A conjuntura do Brasil em meados do século XX se assemelhava com a da França e Inglaterra de pelo menos um século antes. Percebemos uma preocupação semelhante como as possíveis ações das multidões, pessoas reunidas nos movimentos sociais de reivindicação, nas grandes cidades. Isso ficou perceptível, por exemplo, no artigo de Davi Campista Filho, escrito em 1955, no escreveu sobre o possível perigo que representava a "influência das massas que desempenham papel preponderante no mundo atual, inspirando a certos autores sustentarem que a era das massas significa o declínio da civilização, ou o retorno à primitividade" (CAMPISTA FILHO, 1955, p. 446). A massa social, na concepção do mesmo, se distinguiria pela ausência de diferenciação individual, de iniciativa, de originalidade e de consciência.

A massa julga quantidade e não qualidade; e quando julga impulsionar, é apenas impulsionada, intervém no sentido de grandeza física, composta, embora, de seres vivos, que não passam de simples unidades estáticas e que se resolvem em números. Não é ativa, mas puramente receptiva, e não agindo, satisfaz-se em reagir (CAMPISTA FILHO, 1955, p. 446).

Recuperando as ideias de Gustave Le Bon ${ }^{10}$, Davi Campista filho afirmou que a influência

8 Não foi sem razão que a obra do italiano Spicio Sighele, A multidão criminosa: Ensaio de Psicologia Coletiva, escrita no final do século XIX foi traduzida no Brasil em 1954, justamente nessa conjuntura história, marcada por esses movimentos sociais.

9 Estudos como o de Raymond Williams (1989), George Rudé (1991) e Maria Stella Bresciani (2004) nos fornecem elementos necessários para uma possível comparação entre o temor que alguns setores sociais sentiam das multidões reunidas tanto em cidades como Londres e Paris como no Rio de Janeiro e São Paulo.

10 Gustave Le Bon (1841-1931) foi considerado o fundador da Psicologia Social. Suas tentativas para encontrar uma explicação cientificamente aceitável das multidões e das suas ações o notabilizaram. Seus estudos sobre o comportamento coletivo se situam em um contexto social no qual as populações das grandes cidades europeias em 
das massas se formaria e se avultaria pela ação impregnada das características das multidões: "a impulsividade, a irritabilidade, ausência de julgamento e de espírito crítico" (CAMPISTA FILHO, 1955, p. 446). Nesse sentido, "a multidão aparece como a ressurreição de uma horda primitiva, porquanto se desanuvia inteiramente a personalidade consciente perdendo-se a vontade e o discernimento" (CAMPISTA FILHO, 1955, p. 446). Para esse jurista, haveria um hipnotizador que orientaria os sentimentos e os pensamentos das chamadas massas.

As massas geram o pavor dos cegos elementos em fúria, produzindo o terror crescente na abstração das ameaças sinistras e o terror implacável da imensidade infinita do número. Certas unidades, puras, simples, inócuas, são capazes de desencadear calamidades quando assumem o incomensurável - tais como a nuvem de gafanhotos e a invasão de formigas carregadeiras (CAMPISTA FILHO, 1955, p. 446).

Escreveu ainda Davi Campista filho que, devido a essas características das massas, estas poderiam determinar as greves, as quais tinham o poder de influenciar outras pessoas, como um germe que contaminava a todos. O local privilegiado para a propagação desse mal seriam as associações sindicais, nas quais se conseguia a adesão e propagação do movimento grevista. Sendo assim, estas devem ser consideradas elementos extremistas interessados na perturbação da ordem, devendo o Estado se prevenir desse mal através dos órgãos de vigilância. Ainda para o mesmo,

A influência resultante das atitudes das massas que refletem as desordens do mundo econômico, tendente à potencialidade cada vez maior, escapa, todavia, à consciência e discernimento dos próprios interessados. Cada qual sabe que suas exigências chegarão a termo satisfatório à medida que pela sugestão logre abrir caminho a toque de propaganda que, por conquistar a solidariedade, incute à massa força invencível (CAMPISTA FILHO, 1955, p. 447).

Davi Campista filho considerou a propaganda o meio para difundir os movimentos e o indivíduo não mais discerniria entre o verdadeiro e o falso, regredindo ao estado de selvageria e bestialidade. Através da generalização do medo, criar-se-ia uma atmosfera desfavorável a acalmar as emoções que se tornavam furor e ódio, criando nas massas poder de destruição ou de transformação, usando para tal sua arma predileta, a greve.

\section{CONSIDERAÇÕES FINAIS}

Tendo em vista o pressuposto de que os acontecimentos histórico-sociais possuem reflexos importantes no âmbito jurídico, a análise dos artigos escritos por profissionais ligados ao campo do Direito na década de 1950 nos permitiu compreender como os movimentos grevistas

fins do século XIX desafiavam a capacidade do Estado em manter o controle e a ordem social. Le Bon procurou transformar observações descritivas em leis gerais e explicativas do comportamento coletivo nas relações sociais, enfatizando que a mentalidade coletiva poderia dominar um grupo de pessoas e transformá-lo em uma força imprevisível e incontrolável. 
ocorridos naquele período eram vistos por uma parcela dos juristas com grande apreensão, uma vez que as greves eram consideras de caráter violento, sendo associadas às guerras. Além disso, percebemos o receio em relação às "multidões" reunidas nos grandes centros urbanos, consideradas potencialmente criminosas.

Discussões sobre os aspectos constitucionais das greves se fez presente em praticamente todos os artigos utilizados como fonte nessa pesquisa, sendo ora veemente criticados, ora defendidos, mesmo que parcialmente. As críticas foram empreendidas por Paulo Carneiro Maia (1953), que considerava o direito de greve conflitante com o princípio penal que vedava o ato de fazer justiça com as próprias mãos, além de ser desnecessário justamente porque a Justiça do Trabalho era a encarregada de resolver os problemas entre patrões e empregados. Do mesmo modo, Carlos Medeiros Silva (1954), mencionando a regulamentação do direito de greve, se posicionou contrário às mesmas, considerando-as uma forma violenta de reivindicação. E esse foi o mesmo posicionamento de Davi Campista Filho (1955), que considerou, inclusive, perigoso o influxo da declaração constitucional.

Ainda sobre os aspectos constitucionais da greve, na direção oposta dos juristas acima mencionados, temos algumas defesas. Idélio Martins (1954), por exemplo, ressaltouque proclamação do direito de greve pela Constituição de 1946 representou um rompimento com as amarras do passado e com o regime do governo de Vargas, considerado por ele de características totalitárias. Já Seabra Fagundes (1954) entendeu que a regulamentação do direito era o reconhecimento de um direito social do trabalhador e considerou as greves um fenômeno social de forças inelutáveis, contra o qual as leis não podiam resistir. No entanto, sua defesa era parcial, pois não aceitava as greves nos serviços públicos e nem tão pouco as greves que chamou de políticas.

Em se tratando do aspecto político das greves, apreendemos algumas críticas. Muitas das greves ocorridas em meados do século XX tinham o apoio de líderes do Partido Comunista Brasileiro (PCB), que estava na ilegalidade nesse período. Sendo assim, eram desqualificadas em sua real intenção. Para Carlos Medeiros Silva (1954), por exemplo, a greve seria uma manifestação contestadora da ordem política vigente e de caráter revolucionário. Do mesmo modo Seabra Fagundes (1954) afirmou que as greves as quais considerava políticas eram subversivas e, portanto, não deveriam ser contempladas pelo direito de greve expresso na Constituição de 1946. Ideia que é bastante discutível, se compararmos com os tempos atuais, já que a partir da CF de 1988 a greve se tornou um direito constitucional da classe trabalhadora brasileira.

De fato, com a Constituição de 1946, pela primeira vez na história do Brasil, o direito de greve foi constitucionalizado. Desse modo, o referido diploma legal reconheceu um direito que já existia e que era criminalizado em tempos passados. No entanto, a constitucionalização do direito de greve e o clima de reconciliação, típico de um processo de anistia, não impediu a violência do governo contra os grevistas. O clima de guerra fria e a posterior cassação do Partido Comunista do Brasil, indicavam que os tempos não seriam de respeito aos direitos dos grevistas, por mais que o direito fosse constitucionalizado. 


\section{REFERÊNCIAS}

BOURDIEU, Pierre. A economia das trocas linguísticas. São Paulo: EDUSP, 1998.

BRASIL. [Constituição (1946)]. Constituição dos Estados Unidos do Brasil (de 18 de setembro de 1946). Brasília, DF: Presidência da República, 1946. Disponível em: http://www. planalto.gov.br/ccivil_03/constituicao/constituicao46.htm. Acesso em: 2 jul. 2016.

BRESCIANI, Maria Stella M. Londres e Paris no século XIX: o espetáculo da pobreza. São Paulo: Brasiliense, 2004. (Tudo é História, 52).

CAMPISTA FILHO, Davi. O direito de greve e a advertência dos fatos. Revista Forense, Rio de Janeiro, v. 159, p. 441-448, maio/jun. 1955.

CORRÊA, Larissa Rosa. A tessitura dos direitos: patrões e empregados na Justiça do Trabalho. São Paulo: LTr, 2011.

COSTA, Hélio da. Em busca da memória: comissão de fábrica, partido e sindicato no pósguerra. São Paulo, Scritta, 1995.

DELGADO, Maurício Godinho; DELGADO, Gabriela Neves. Justiça do Trabalho: 70 anos de justiça social. Revista TST, Brasília, v. 77, n. 2, abr./jun. 2011.

DUBY, Georges. História social e ideologias das sociedades. In: LE GOFF, Jacques; NORA, Pierre. História: novos problemas. Tradução de Theo Santiago. 2. ed. Rio de Janeiro: Francisco Alves, 1979. p. 130-145.

FAGUNDES, Seabra. O direito de greve. Revista Forense, Rio de Janeiro, v. 154, p. 12-17, jul./ ago. 1954.

GINZBURG, Carlo. Sinais: raízes de um paradigma indiciário. In: GINZBURG, Carlo. Mitos, emblemas e sinais: morfologia e história. 2. ed. São Paulo: Companhia das Letras, 2003 p. 143 179.

MAIA, Paulo Carneiro. Aspectos constitucionais da greve. Revista dos Tribunais, São Paulo, v. 208, p. 3-21, fev. 1953.

MARTINS, Idélio. Sobre as greves e seus efeitos no contrato de trabalho. Revista dos Tribunais, São Paulo, v. 222, p. 3-30, abr. 1954.

MATTOS, Marcelo Badaró. Greves, sindicatos e repressão policial no Rio de Janeiro (19541964). Revista Brasileira de História, São Paulo, v. 24, n. 47, p. 241-270, 2004.

MOISÉS, José Álvaro. Greve de massa e greve política: estudo da Greve dos 300 mil em São Paulo: 1953/54. São Paulo: Livraria Editora Polis, 1978.

NEDER, Gizlene. Discurso jurídico e ordem burguesa no Brasil. Porto Alegre: Sérgio Antônio Fabris, 1995.

NEGRO, Antônio Luigi; SILVA, Fernando Teixeira da. Trabalhadores, sindicatos e política. In: FERREIRA, Jorge; DELGADO, Lucília de Almeida Neves (org.). O tempo da experiência 
democrática: da democratização de 1945 ao golpe civil-militar de 1964. Rio de Janeiro: Civilização Brasileira, 2008. p. 47-96. (O Brasil Republicano, v.3).

RUDÉ, George. A multidão na história: estudo dos movimentos populares na França e na Inglaterra 1730-1848. Rio de Janeiro: Campus, 1991.

SIGHELE, Spicio. A multidão criminosa: ensaio de psicologia criminosa. Rio de Janeiro: Organizações Simões, 1954.

SILVA, Carlos Medeiros. A regulamentação do direito de greve. Revista Forense, Rio de Janeiro, v. 154, p. 7-11, jul./ago. 1954.

SIQUEIRA, Gustavo Silveira. SIQUEIRA, Gustavo Silveira. História do direito pelos movimentos sociais: cidadania, antropofagia e experiências jurídicas nas estradas de ferro (Brasil, 1906). Rio de Janeiro: Lumen Juris, 2014.

WILLIAMS, Raymond. O campo e a cidade na história e na literatura. São Paulo: Companhia da Letras, 1989.

Como citar: GONÇALVES, Patrícia Graziela; PRIORI, Angelo Aparecido. Percepções jurídicas acerca dos movimentos grevistas no Brasil em meados do século XX. Revista do Direito Público, Londrina, v. 14, n. 1, p. 121-138, abr. 2019. DOI: 10.5433/1980-511X2019v14n1p121. ISSN: 1980-511X.

Recebido em:22/07/2016.

Aprovado em: 28/01/2019. 